\title{
INFLUENCE OF FOOT POSITION IN THE PERFORMANCE OF SIT TO STAND IN POST STROKE HEMIPARETIC PATIENTS
}

\author{
Claudia Costa Pinto Furtado Machado*, Moema Pires Guimarães Soares**, Gabriel Venas Santos***, \\ Elen Beatriz Carneiro Pinto**** \\ Autor correspondente: Claudia Costa Pinto Furtado Machado. E-mail: ccpsfurtadol@bahiana.edu.br \\ * Escola Bahiana de Medicina e Saúde Pública \\ ** Fisioterapêuta, professora assistente do curso de Fisioterapia e Medicina da Escola Bahiana de Medicina e Saúde Pública \\ e Mestre em Ciências da Família pela Universidade Católica do Salvador \\ *** Acadêmico do curso de Fisioterapia da Escola Bahiana de Medicina e Saúde Pública. \\ **** Fisioterapêuta, Doutora em Ciências da Saúde pela Universidade Federal da Bahia e professora da graduação e pós \\ graduação da Escola Bahiana de Medicina e Saúde Públca
}

\begin{abstract}
Background: Sit to stand is one of the functional tasks that may have been altered in post stroke hemiparetic patients. This transfer may have been altered affected by various extrinsic conditions, among them the position of the feet. Objective: systematize the knowledge about the influence of foot placement in the performance of standing up in post stroke hemiparetic patients. Method: a non systematic review in the period of March to September 2014 was performed, including original articles published from January 2002 to September 2014. Results: 35 articles were found, 8 met the inclusion criteria and were included, 6 of them of observational feature, 1 controlled biomechanical experiment and 1 randomized clinical trial. Conclusion: the findings suggest that the choice of foot position interferes in the standing up performance. This aspect should be considered for the evaluation and treatment, allowing the control of variables that interferes on the performance of this task.

Keywords: Stroke; Foot position; Sit- to- stand.
\end{abstract}

\section{INTRODUCTION}

The Stroke is considered as a common cause for mobility reduction and deficit in the execution of daily activities. (1) Hemiparesis is the most clear dysfunction after stroke (2) and it is characterized by sensorial changes, muscle weakness, postural control impairment and 
weight bearing distribution asymmetry. (3,4) All of these changes converge for the development of functional incapacity and gait and raise impairment, are the main aggravating factors of the incapacity. $(3,5)$

The task of sit to stand from a chair can be altered in hemiparetic patients. They frequently use the pattern of asymmetrical weight bearing during this movement and it takes more time to do $\mathrm{so}^{(3,4)}$ and this transfer can be affected by various extrinsic conditions, among them the foot position. ${ }^{(6,8)}$ Previous studies show that training of rising with the paretic foot posterior to the non paretic (non stricken) induced the gain in performance efficiency, functional mobility and balance when compared to the symmetric foot position. (9)

Considering the importance on the motion of standing up as pre requisite to functional independence of people, ${ }^{(7)}$ the identification of movement determinants that influence in the performance of this task is primordial when choosing appropriate strategies to proper facilitation of this transfer. The purpose of this paper is to systematize the knowledge about the influence of foot position in the performance of standing up in hemiparetic patients post stroke.

\section{METHOD}

It is a non systematic review, which search was performed using Scielo and Medline database by Pubmed and virtual library Capes. The data gathering was realized in the period of March to September 2014. The key words used were stroke, foot position and sit-to-stand and their correlates in Portuguese/English.

Original articles published from January 2002 to September 2014 were included, and they addressed the influence of foot position in the performance of sit-to-stand transfer in hemiparetic post stroke individuals. The articles that only addressed the sitto-stand transfer in stroke patients and those that correlated the raising only with the seat height or knee angle were excluded.

\section{RESULTS}

Thirty five articles that addressed the standing up motion in hemiparetic patients post stroke were found, 27 were excluded for they didn't address the foot position relation with the performance of standing up in hemiparetic patients after stroke. Eight articles were included, 6 of them observational, 1 controlled biomechanical experiment and 1 randomized clinical trial (Image oı).

Image 1 - Flowchart

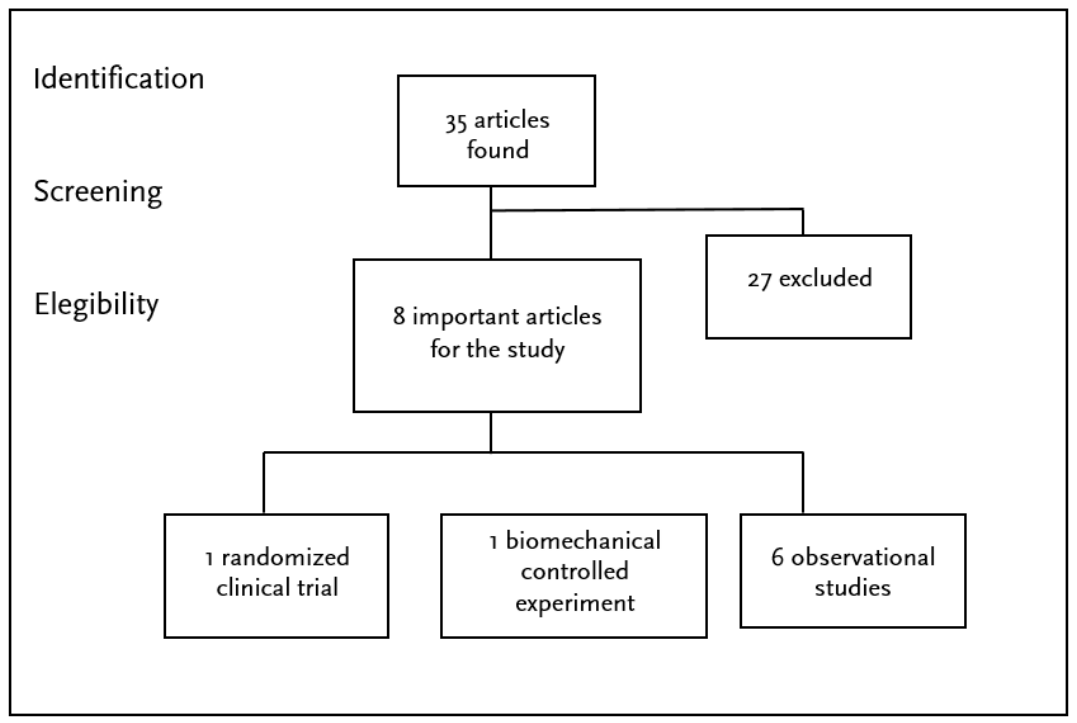


Three studies used spontaneous positions (without instructions about the initial position of the feet), symmetric (with 15 degrees of feet dorsiflexion) and asymmetric (with the paretic foot behind the non affected and the unaffected foot behind the paretic). $(8,10,11)$ Another author performed a study on the same positions, but used the asymmetric moment only with the paretic foot behind the unaffected. ${ }^{(12)}$

Some studies were performed only with two positions: spontaneous and asymmetric (with the paretic foot behind the uninvolved), ${ }^{(13)}$ symmetric and asymmetric, ${ }^{(9)}$ and normal (knee at 90 degrees and neutral ankle) and posterior (both heels 10 $\mathrm{cm}$ behind the normal position). ${ }^{(14)}$ Only one study considered the member position in the normal condition (both members were positioned so that the knee flexion were 100 degrees), in the extended condition (non-affected member was positioned so that the knee stayed 75 degrees of flexion and the paretic limb remained at 100 degrees of flexion) and in a elevated condition (the unaffected limb was positioned in a dense foam while the paretic was flat on the floor with the knee flexion to 100 degrees). These conditions determined the foot position (15). (Table o1)

Table 1 - Relation of foot position and variables of the performance on the transfer from a sit-to-stand position.

Performance on the transfer from a sit-to-stand position

\begin{tabular}{|c|c|c|c|c|c|c|c|c|c|}
\hline AUTHOR & $\begin{array}{c}\text { METHOD/ } \\
\text { INSTRUMENTS OF } \\
\text { MEASUREMENT }\end{array}$ & FEet Position & $\mathrm{L}$ & Ass & J.M.A & E.M.G & D. T & B.M & N. R \\
\hline Roy et & Force platform and & Spontaneous & & & & & & & \\
\hline \multirow[t]{2}{*}{$\mathrm{al}(2006)$} & Optotrak 302O System & symmetric & & & & & & & \\
\hline & & Asymmetric I / II & $x$ & $x$ & & & & & \\
\hline Roy et al & Force platform and & Spontaneous & & & & & & & \\
\hline \multirow[t]{2}{*}{$(2007)$} & Optotrak 3020 System & symmetric & & & & & & & \\
\hline & & Asymmetric I / II & & & $x$ & & & & \\
\hline Lecours et al & Force platform and & spontaneous & & & & & & & \\
\hline \multirow[t]{2}{*}{$(2008)$} & Optotrak 302O System & Symmetric & & & & & & & \\
\hline & & Asymmetric & & $x$ & $x$ & & & $x$ & \\
\hline Kwong et al & Five times sit-to-stand & Normal & & & & & & & \\
\hline (2O14) & test time & Posterior & $x$ & & & & & & \\
\hline Camargos & EMG (MP150wsw) & Spontaneous & & & & & & & \\
\hline \multirow[t]{2}{*}{ et al (2009) } & Balance Master System & Symmetric & & & & & & & \\
\hline & Triaxial accelerometer & Asymmetric I /II & $x$ & $x$ & & $x$ & & & \\
\hline Farqalt & Repetition counting & Symmetric & & & & & & & \\
\hline et al (2O13) & & Asymmetric & & & & & & & $x$ \\
\hline Duclos et al & Force platform and & Spontaneous & & & & & & & \\
\hline (2008) & Optotrak 3020 System & Asymmetric & & & & & $x$ & & \\
\hline Brunt et al & Electromyography & Normal condition & & & & & & & \\
\hline \multirow[t]{2}{*}{$(2 \mathrm{OO} 2)$} & Force platform & Extended condition & & & & & & & \\
\hline & & Elevated condition & $x$ & & & $x$ & & & \\
\hline
\end{tabular}

$\mathrm{L}=$ Length of the raise; Ass = Asymmetry; J.M.A = Joint moment asymmetry; E.M.G = electromyography; $\mathrm{D}$ = displacement; B.M = Body movement; N.R = number of repetitions of the raise.

Source: research data 


\section{DISCUSSION}

Through this review it was found that there was an influence among the different positions of the feet on the performance of the standing up in hemiparetic subjects after stroke. Three studies using the positioning foot strategies, found shorter time in the performance of standing up from spontaneous position when compared to the symmetric and asymmetric in hemiparetic patients. $(8,11,13)$ The duration to complete the task on the spontaneous position of feet on the above studies was shorter $(2,6 ; 2,7$ and 1,93 s) than reported by Chou e outros, ${ }^{(5)}$ 2003, in his study about hemiparetic subjects $(4,5 \mathrm{~s})$.

A recent study examining the position of feet and arms during the five times sit-to-stand test showed that posterior position of feet compared to the normal position, exhibited shorter duration and therefore a better performance, regardless the position of the arms. ${ }^{(14)}$ Corroborating with these findings, a study showed the posterior positioning of foot allows a more efficient movement of standing up with reduction of anterior displacement of body gravity center. ${ }^{(16)}$ Furthermore Brunt e outros, ${ }^{(15)}$ 2002 reported an increase in this time when the paretic limb was behind the uninvolved and even more when the uninvolved was in a more elevated position than the paretic.

Hemiparetic individuals showed differences in vertical reaction forces and knee joint moment between the sides, the spontaneous, symmetrical and asymmetrical positions of the feet, but was less marked in the asymmetric position. ${ }^{(12)}$ The asymmetric position of the feet, with the paretic foot positioned behind the uninvolved, largely reduced the difference in the distribution of the vertical reaction force. ${ }^{\left({ }^{8}\right)}$ This fact was also observed by Roy e outros, ${ }^{(10)} 2007$, decrease in the net joint moment asymmetry between sides, especially in the transition phase and loss of contact with the seat. On the other hand, recent studies shown a reduction in weight distribution and knee joint moment symmetry measure between the sides in healthy young subjects in the asymmetric position when compared with the symmetric, ${ }^{(19)}$ but this results divergence is attributed to the different characteristics of population between studies, as hemiparetic and healthy young people were studied, respectively.

Other authors found that hemiparetic subjects showed no difference in simetric weight distribution, regardless of foot position used, concluding that the foot position on the motion of standing up from a seated position should not be a relevant factor for functional performance of these individuals. (11) The divergence of results can be explained by the sample of chronic hemiparetic subjects, using different motor control strategies promoting the performance.

Another aspect associated with the difference in weight bearing and the failure in the perception of this distribution in hemiparetic subjects, was the strength of the knee extensors. ${ }^{(18)}$ Evidence suggests that muscle strength (especially the concentric activity of the knee extensors and ankle extensor and flexor eccentric plantar) and the weight distribution skill in the paretic side are important factors in the ability of standing up. ${ }^{(3)}$ The distribution of weight to the paretic foot may favor more tactile and proprioceptive stimulation optimizing the sensory information about joint moment, which would allow member position adjustment.

According to Duclos e outros, ${ }^{(13)} 2008$, standing up with the asymmetrical position of feet (paretic foot behind the unaffected one), compared to the spontaneous positioning, enabled reduction of lateral deviation of the center of pressure and shoulders for the unaffected side and oscillation of the body in the frontal plane during the first $25 \%$ of the task. There was no significant change in the displacement of the pelvis when compared to the two positions of the feet. Studies using the same asymmetric positioning of the feet, confirmed these findings. ${ }^{(8,12)}$

After stroke automatic program to get up may be compromised by muscle weakness in the paretic side. ${ }^{(5)}$ Study investigated the relationship of muscle strength with the transfer from sitting to 
standing identified the association of paretic knee extensors and ankle extensors with the performance of standing up in subjects after stroke. ${ }^{(3)}$ The biomechanical experiment of Brunt e outros, ${ }^{(15)}$ 2002, showed higher electromyographic activity of the anterior tibial and quadriceps in the paretic limb, with this limb behind the uninvolved and the unaffected one in a higher position in relation to paretic.

Lower electromyographic activity of the hamstrings in symmetric position and higher in the asymmetric and spontaneous position, were found in an observational study that evaluated the effect of foot position on the performance of standing up in hemiparetic subjects. It was not found significant differences between the position of feet and quadriceps and anterior tibial. ${ }^{(11)}$ The same study reports that lower activity of the hamstrings is indicative that the posterior positioning of both feet, in other words, in the symmetrical position, reduced the need of joint stabilization. In addition the authors found that the onset of soleus activation was delayed in the asymmetric position (unaffected foot behind the paretic) compared with the spontaneous and that it was activated before the loss of contact with the seat.

Corroborating with this study another author found that in healthy individuals the anterior tibial muscle was the first one to be activated, followed by the quadriceps, hamstrings and finally the soleus. However in hemiparetic subjects, this muscle group was activated almost simultaneously, considering that this pattern of activation of the muscles is due to extensor synergy in these patients, involving the hamstrings, quadriceps and soleus, acting on the hip, knee and ankle, respectively. ${ }^{(19)}$

A randomized clinical trial demonstrated that the training of standing up for four weeks in a group with their feet in the asymmetric position resulted in an increase in the number of repetitions of the task, when compared with the group that trained with the symmetrical position of the feet.(9) This study reported an increased number of repetitions of a three minute break so to perform more repetitions within this range it is assumed that the individual has increased the speed of the transfer from a sit-tostand position. The completion of standing up with the asymmetric foot position provides a greater degree of anteroposterior stability, thereby allowing the movement to be performed at a higher speed. ${ }^{(20)}$

\section{CONCLUSION}

The findings suggest that the choice of the foot position affects the performance of the task of sit to stand. This should be considered in the evaluation and treatment, enabling to control the variables that affect the performance of this task. One limitation of this study is that we highlight the lack of methodological standardization among studies to establish more insightful conclusions.

\section{REFERENCES}

1. Pinto E B, Maso I, Pereira J LB, Fukuda T G, Seixas J C, Menezes D F, Cincura C, Neville IS, Jesus P AP, Oliveira-Filho J. Differential aspects of stroke and congestive heart failure in quality of life reduction: a case series with three comparison groups. Health and Quality of Life Outcomes. 2011;9:65. [cited 2015]. Available from: http://www.hqlo.com/content/9/1/65

2. Trindade A P N T, Barboza M A, Oliveira F $B$, Borges A P O. Influência da simetria e transferência de peso nos aspectos motores após Acidente Vascular Cerebral. Rev Neurociências. 2011;19;61-67.

3. Lomaglio M J, Eng J J. Muscle strength and weight - bearing symmetry relate to sit- tostand performance in patients stroke. Gait Posture. 2005;22:126-131. DOI:10.1016/j. gaitpost.2004.08.002

4. Wagner J M, Lang C E, Sahrmann S A, Edwards D F, Dromerick A W. Sensorimotor impairments and reaching performance in subjects with post stroke hemiparesis during the first few months of recovery. Physical Therapy. 2007;87(6):751-765. [cited 2015]. Available from: http://ptjournal. 
apta.org/content/87/6/751/DOI: 10.2522/ ptj.20060135

5. Chou S W, Wong A M. K, Leong C P, HONG W S, Tang, F T, Lin T H. Postural control during sit-to-stand and gait in stroke patients. American Journal of Physical Medicine \& Rehabilitation. 2003;82:42-47. DOI: 10.1097/O1. PHM.0OOOO43769.93584.4D

6. Lee M Y, Lee, H Y. Analysis for Sit-to-Stand Performance According to the Angle of Knee Flexion in Individuals with Hemiparesis. Journal Physical Therapy Sciense. 2013;25:1583-1585.

7. Mazzá C, Croce U D. Sequencing sit to stand and upright posture for mobility limitation assessment: determination of the timing of the task phases from force platform data. Gait \& Posture.2005;21:425-431. [cited 2015]. Available from: http://www.sciencedirect.com/ DOI:1016/j.apmr.2005.12.037

8. Roy G, Nadeau S, Gravel D, Malouin F, Mcfadyen B, Piotte F. The effect of foot position and chair height on the asymmetry of vertical forces during sit to stand and stand to sit tasks in individuals with hemiparesis. Clinical Biomechanics. 2006;21:585-593. [cited 2015]. Available from: http://www.sciencedirect.com/ DOI:10.1016/j.clinbiomech.2006.01.007

9. Farqalit R, Shahnawaz A. Effect of position during sit to stand training on balance and upright mobility in patients with chronic stroke. Hong Kong Physiotherapy Journal. 2013;31:75-80. [cited 2015]. Available from: http://www.sciencedirect.com/Doi:10.1016/j. hkpj.2013.06.001

10. Roy G, Nadeau S, Gravel D, Malouin F, Mcfadyen B, Piotte F. Side difference in the hip and knee joint moments during sit to stand and stand to sit tasks in individuals with hemiparesis. Clinical Biomechanics. 2007;22:795-804. [cited 2015]. Available from: http://www.sciencedirect. com/DOI:10.1016/j.clinbiomech.2007.03.007

11. Camargos A C, Gourlat F R P, Salmela L F. T. The effect of foot position on the performance of the sit to stand movement with chronic stroke subjects. Arch Phys Med Rehabil. 2009; 90:31432O. DOI:10.1016/j.apmr.2008.06.023

12. Lecours J, Nadeau S, Gravel D, Teixeira- Salmela L. Interactions between foot placement, trunk frontal position, weight-bearing and knee moment asymmetry at seat-off during rising from a chair in healthy controls and persons with hemiparesis. J Rehabil Med. 2008;40: 200-2O7. DOI: 10.2340/16501977-0155

13. Trunk Displacement and Stability During Sit-to-Stand Transfer in Relation to Foot Placement in Patients With Hemiparesis. Neurorehabilitation and Neural Repair. 2008. DOI:10.1177/1545968308316000

14. Kwong P W, Ng S S M, Chung R C K, Ng G Y. Foot Placement and Arm Position Affect the Five Times Sit-to-Stand Test Time of Individuals with Chronic Stroke. BioMed Research International. 2014. [cited 2015]. Available from: http://dx.doi.org/10.1155/2014/636530

15. Brunt D, Greenberg B, Wankadia S, Trimble M A, Shechtman O. The Effect of Foot Placement on Sit to Stand in Healthy Young Subjects and Patients with Hemiplegia. Arch Phys Med Rehabil. 2002;83:924-929. DOI: doi:10.1053/ apmr.2OO2.3324

16. Kawagoe S, Tajima N, Chosa E. Biomechanical analysis of effects of foot placement with varying chair height on the motion of standing up. Journal of Orthopedic Science.2000;5:124-133.

17. Gillete J C, STERVEMER C A. The effects of symmetric and asymmetric foot placements on sit to stand joint moments. Gait \& Posture.2O12;35:78-82. DOI: 10.1016/j. gaitpost.2011.08.010

18. Briere A, Lauziere S, Gravel D, Nadeau S. Perception of Weight-Bearing Distribution During Sit-to-Stand Tasks in Hemiparetic and Healthy Individuals. Stroke. 2010;41:1704-1708. DOI: 10.1161/STROKEAHA.110.589473

19. Cheng P T, Chen C L, Wang C M, Hong W H . Leg Muscle Activation Patterns of Sit-to-Stand Movement in Stroke Patients. Am. J. Phys. Med. Rehabil. 2004;83:10-16. DOI: 10.1097/01. PHM.0000104665.34557.56

2O. Clark, K G, Kelly S M, Hartley, Wing A. Effect of Foot Position on Acceleration during Sit to Stand. Physiotherapy. 2001;88(3). 